Check for updates

Cite this: New J. Chem., 2017, 41,5271

Received 13th April 2017, Accepted 27th May 2017

DOI: 10.1039/c7nj01237c

rsc.li/njc

\section{Nanoscale hydrophilic colloids with high relaxivity and low cytotoxicity based on Gd(III) complexes with Keplerate polyanions $\dagger$}

\author{
Julia Elistratova, (D)*a Bulat Akhmadeev, ${ }^{\mathrm{b}}$ Aidar Gubaidullin, ${ }^{a}$ Vladimir Korenev, (D) \\ Maxim Sokolov, (D) ${ }^{c}$ Irek Nizameev, ${ }^{a}$ Alexey Stepanov, ${ }^{a}$ Ildus Ismaev, \\ Marsil Kadirov, ${ }^{a}$ Alexandra Voloshina ${ }^{a}$ and Asiya Mustafina ${ }^{a}$
}

The work introduces for the first time Mo-132-type Keplerates (Kp) and $\mathrm{Gd}^{3+}$ ions as a basis for the one-pot synthesis of aqueous colloids with high longitudinal relaxivity $\left(r_{1}=96.4 \mathrm{mM}^{-1} \mathrm{~s}^{-1}\right.$ at $20 \mathrm{MHz})$. The hydrophilic coating of small $(3-5 \mathrm{~nm}) \mathrm{Gd}_{x}(\mathrm{Kp})_{y}$-based cores provides their colloid stabilization, protection from degradation and low cytotoxicity.

Nanoparticulate Gd(III)-based contrast agents (CAs) are at the height of current interest due to their multiple advantages over mononuclear commercial CAs. ${ }^{1-5}$ In particular, Gd complexes packed into nanosized species constitute an alternative basis for CAs, against both $\mathrm{Gd}_{2} \mathrm{O}_{3}$-based nanoparticles and molecular complexes. ${ }^{6-10}$ The packing of Gd complexes into nanoparticles increases relaxivity values due to the slowed down tumbling regime of Gd centers. ${ }^{11}$ Moreover, the packing increases an overall stability of Gd complexes, and restricts both ion and ligand exchange processes, thus significantly reducing their cytotoxicity. Published data indicate better relaxivity values for ultrasmall nanoparticles of $2-4 \mathrm{~nm}$ in size, which highlights an efficient hydration of $\mathrm{Gd}^{3+}$ centres as the key factor facilitating paramagnetic enhancement of water proton relaxation in aqueous $\mathrm{Gd}^{3+}$-based colloids. ${ }^{11}$ The best longitudinal relaxivity $\left(r_{1}\right)$ is reported for the nanocrystalline Gd-based MOFs, where $r_{1}$ at $25{ }^{\circ} \mathrm{C}$ reaches $105.4 \mathrm{mM}^{-1} \mathrm{~s}^{-1}$ at $1.5 \mathrm{~T}^{8}{ }^{8} 69.3 \mathrm{mM}^{-1} \mathrm{~s}^{-1}$ at $4.7 \mathrm{~T}^{6}$ and $83.9 \mathrm{mM}^{-1} \mathrm{~s}^{-1}$ at $3.0 \mathrm{~T}$ and $37{ }^{\circ} \mathrm{C}^{9}$ These values are notably higher than the best $r_{1}$ value reported for $\mathrm{Gd}_{2} \mathrm{O}_{3}$-based

\footnotetext{
${ }^{a}$ A. E. Arbuzov Institute of Organic and Physical Chemistry, Kazan Scientific Center, Russian Academy of Sciences, Arbuzov str., 8, 420088, Kazan, Russia. E-mail: 969_969@bk.ru

${ }^{b}$ Kazan (Volga region) Federal University, Kremlyovskaya str., 18, 420008, Kazan, Russia

${ }^{c}$ Nikolaev Institute of Inorganic Chemistry, 3 Acad. LavrentievProsp., Novosibirsk, Russia

${ }^{d}$ A. N. Tupolev, Kazan National Research Technical University, 10, K. Marx St., Kazan, 420111, Russia

$\dagger$ Electronic supplementary information (ESI) available: Synthesis of Keplerate salts, Raman and UV-Vis spectra, PXRD, SAXS, DLS and magnetic relaxation data. See DOI: $10.1039 / \mathrm{c} 7 \mathrm{nj} 01237 \mathrm{c}$
}

nanoparticles ${ }^{12}\left(38 \mathrm{mM}^{-1} \mathrm{~s}^{-1}\right)$, while the values of the commercial CAs are lower than $10 \mathrm{mM}^{-1} \mathrm{~s}^{-1}$. ${ }^{11}$ The higher relaxivity of the MOF-based nanoparticles highlights an impact of crystalline water molecules as the factor notably enhancing the relaxivity of water molecules in corresponding aqueous colloids. ${ }^{7}$

Anionic complexes, clusters and polyoxometalates are promising alternatives to organic ligands, although their applicability in the design of new Gd(III) CAs has been exemplified in very few reports. ${ }^{13-15}$ Electroneutrality of such complexes is worth noting as a reason for their transformation from the molecular to nanoparticulate form. The keplerates (Kp), firstly introduced by Müller and coworkers, are a versatile type of anionic molybdenum oxide-based nanocapsules with icosahedral symmetry ${ }^{15}$ Their very high negative charge along with efficient binding sites for metal ions, both inside and outside the polyoxometalate capsule, meet the prerequisites for their use as inorganic ligands for Gd(III) CAs. ${ }^{16}$ The work of Zhang and coworkers ${ }^{17}$ is in particular worth noting as it highlights the potential binding sites for $\mathrm{Gd}^{3+}$ ions on the surface and inside a keplerate capsule, and the retention of high hydration numbers upon coordination of Gd(III), thus validating the idea of using Gd(III) complexes with keplerates as promising building blocks for nanoparticulate Gd(III)-based CAs.

Efficient hydrophilization of the Gd-based nanoparticles in the framework of a core-shell morphology is a reason for high stability of their aqueous colloids, which enables the measurement of their relaxivity without using xanthan or agar gels. ${ }^{8,9}$ Water soluble polymers possessing ionized groups and/or polyethyleneoxide moieties are promoted as efficient building blocks for the hydrophilic coating. ${ }^{18-20}$ The present work introduces synthetic conditions for bottom-up self-assembly of keplerate-based polyanions, $\mathrm{Gd}^{3+}$ ions and triblock copolymers, which resulted in hydrophilic aqueous colloids with very high (82.0-96.5 $\mathrm{mM}^{-1} \mathrm{~s}^{-1}$ ) longitudinal relaxivity at $20 \mathrm{MHz}$, high colloid stability and low cytotoxicity.

For these reasons, the ammonium salt of a keplerate $\left[\left\{\left(\mathrm{Mo}^{\mathrm{V}} \mathrm{I}\right) \mathrm{Mo}^{\mathrm{VI}}{ }_{5} \mathrm{O}_{21}\left(\mathrm{H}_{2} \mathrm{O}\right)_{6}\right\}_{12}\left\{\mathrm{Mo}_{2} \mathrm{O}_{4} \mathrm{O}_{4}\left(\mathrm{CH}_{3} \mathrm{COO}\right)\right\}_{30}\right]^{42-}(\mathrm{Kp})$ was synthesized in accordance with the previously reported procedure 
(see the ESI $\dagger$ for more details). ${ }^{15}$ The structure of $\left(\mathrm{NH}_{4}\right)_{42} \mathrm{Kp}$ was verified by X-ray and Raman spectroscopy data (Fig. S1, ESI $\dagger$ ). Gadolinium chloride was added to the aqueous solution of $\left(\mathrm{NH}_{4}\right)_{42} \mathrm{Kp}$, resulting in immediate precipitation of the product. The Raman spectrum proves that the Kp anion remains unchanged (Fig. S2 in the ESI $\dagger$ ) in the product. According to elemental analysis (no nitrogen in the sample), and the atomic ratio $\mathrm{Mo:} \mathrm{Gd}=9.3$, determined by ICP-AES, the product was formulated to be $\mathrm{Gd}_{14}\left[\left\{\mathrm{Mo}_{6} \mathrm{O}_{21}\left(\mathrm{H}_{2} \mathrm{O}\right)_{6}\right\}_{12}\left\{\mathrm{Mo}_{2} \mathrm{O}_{4}\left(\mathrm{CH}_{3} \mathrm{COO}\right)\right\}_{30}\right] \cdot 200 \mathrm{H}_{2} \mathrm{O}$, thus full charge neutralization is achieved with $\mathrm{Gd}^{3+}$. The charge neutralization is the basis for the formation of colloid $\mathrm{Gd}_{x}(\mathrm{Kp})_{y}$ species under specific conditions restricting incontrollable growth and aggregation in aqueous solutions. The size of the $\mathrm{Gd}_{x}(\mathrm{Kp})_{y}$-based species (the charge is omitted for clarity) can be manipulated by adjusting the concentrations of both keplerate and $\mathrm{Gd}^{3+}$ ions. Indeed, continuous feeding of $\mathrm{Gd}^{3+}$ to the aqueous solution of $\left(\mathrm{NH}_{4}\right)_{42} \mathrm{Kp}$ under vigorous stirring at specific concentrations $\left(0.007\right.$ and $0.08 \mathrm{mM}$ for $\mathrm{Kp}$ and $\mathrm{Gd}^{3+}$, respectively) results in the formation of colloids. Dynamic light scattering (DLS) measurements of these colloids indicate $200 \pm 10 \mathrm{~nm}$-sized species with a negative electrokinetic potential $(\zeta=-22 \pm 1 \mathrm{mV})$ value and a low polydispersity index (PDI $=0.06)$ (Fig. S3 in the ESI $\dagger$ ). The negative surface charge results from incomplete charge neutralization, which can arise from insufficient amount of $\mathrm{Gd}^{3+}$ ions for full charge neutralization of $\mathrm{Kp}$ polyanions (from the molar ratio $\mathrm{Gd}^{3+} / \mathrm{Kp}=11.4$, it can be calculated that only $c a .33$ charge units of Kp out of 42 are compensated with $\mathrm{Gd}^{3+}$ ). Nevertheless, the remaining surface charge of the $\operatorname{Gd}_{x}(\mathrm{Kp})_{y}$-based species is insufficient for colloid stabilization, which is the reason for their aggregation, followed by precipitation in several hours. Powder X-ray diffraction (PXRD) analysis of dried samples of the colloids reveals a semicrystalline state of the $\mathrm{Gd}_{x}(\mathrm{Kp})_{y}$-based species (Fig. S4 in the ESI $\dagger$ ).

These $\mathrm{Gd}_{x}(\mathrm{Kp})_{y}$-colloids tend to undergo rather fast destruction in diluted aqueous solutions. ${ }^{21}$ The decay was monitored by UV-Vis spectroscopy at the wavelength of the electronic absorption band (455 $\mathrm{nm}$ ) peculiar for $\mathrm{Kp}$ in aqueous solutions (Fig. S5, ESI $\dagger$ ). The $A / A_{0}$ values, measured for the naked $\mathrm{Gd}_{x}(\mathrm{Kp})_{y}$ aqueous colloids as a function of time (Fig. 1), indicate that the
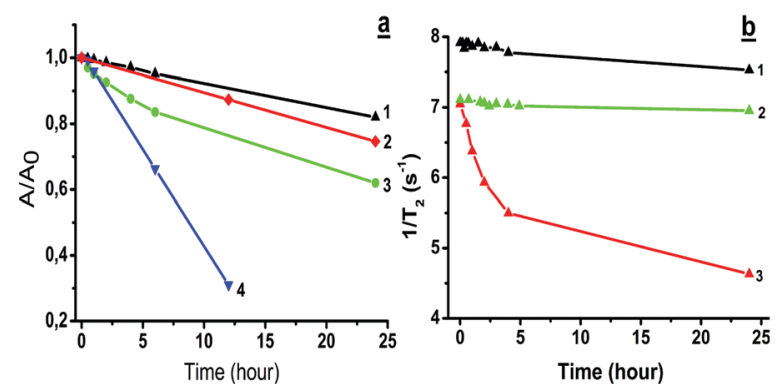

Fig. 1 (a) Destruction of $\mathrm{Gd}_{x}(\mathrm{Kp})_{y}(0.007$ and $0.08 \mathrm{mM}$ for $\mathrm{Kp}$ and $\mathrm{Gd}^{3+}$, respectively) monitored using $A / A_{0}$ values for $\mathrm{F}-127$-stabilized (1), P-123-stabilized (2) and F-68-stabilized (3) and in aqueous solutions without stabilization (4). $1 / T_{2}$ monitored in time for $\mathrm{Gd}_{x}(\mathrm{Kp})_{y}$ stabilized by P-123 (1), F-127 (2) and F-68 (3) at $0.5 \mathrm{mM}$ of P-123, $0.08 \mathrm{mM} \mathrm{F-127,}$ and $0.12 \mathrm{mM}$ of $\mathrm{F}-68$. decay of the $\mathrm{Kp}$ part of $\mathrm{Gd}_{x}(\mathrm{Kp})_{y}$ is significant. Both the colloid instability and the quick destruction may be restricted by making a hydrophilic shell of $\mathrm{Gd}_{x}(\mathrm{Kp})_{y}$ cores.

Some representatives of the triblock copolymer series, containing polyethyleneoxide (PEO) and polypropyleneoxide (PPO) moieties, namely $(\mathrm{PEO})_{100^{-}}(\mathrm{PPO})_{65^{-}}(\mathrm{PEO})_{100}(\mathrm{~F}-127),(\mathrm{PEO})_{75^{-}}$ $(\mathrm{PPO})_{30}-(\mathrm{PEO})_{75}(\mathrm{P}-123)$, and $(\mathrm{PEO})_{20}-(\mathrm{PPO})_{70}-(\mathrm{PEO})_{20}(\mathrm{~F}-68)$, were chosen as the building blocks for the hydrophilic shell due to their low cytotoxicity and capacity to aggregate into micelles at room temperature. Critical micellar concentration (CMC) values are 0.025 and $0.55 \mathrm{mM}$ for P-123 and F-127, respectively. ${ }^{22,23}$ The micellization of F-68 is observed in more concentrated solutions, although the CMC values vary from 0.48 to $1.4 \mathrm{mM}$ in different reports. ${ }^{24,25}$ The concentrations of the triblock copolymers were optimized with the aim to gain in the stability of the $\operatorname{Gd}_{x}(\mathrm{Kp})_{y}$ colloids (Fig. S5 in the ESI $\dagger$ ). Fig. 1 compares the $A / A_{0}$ values measured for the aqueous colloids of the naked $\operatorname{Gd}_{x}(\mathrm{Kp})_{y}$ and those stabilized by the triblock copolymers as a function of time. The results indicate that for each triblock copolymer a specific concentration is required for a desired level of stabilization of $\mathrm{Gd}_{x}(\mathrm{Kp})_{y}$ : in our case, to achieve acceptably slow degradation within 24 hours. The required concentration of F-127 is $0.08 \mathrm{mM}$, which hardly exceeds the corresponding CMC value. In contrast, a higher concentration of P-123 $(0.5 \mathrm{mM})$ is required for the same level of stabilization, while for F-68 the degradation is still significant even at $0.12 \mathrm{mM}$ level.

Micelles of the triblock copolymers appear in dynamic light scattering (DLS) measurements as $15 \pm 5 \mathrm{~nm}$ sized aggregates. ${ }^{26}$ The DLS measurements reveal small changes in the diameter for $\mathrm{P}-123-\mathrm{Gd}_{x}(\mathrm{Kp})_{y}(25 \pm 5 \mathrm{~nm})$, while larger-sized aggregates $(50 \pm 7 \mathrm{~nm})$ are detected in F-127- and F-68stabilized colloids (Fig. S6, ESI $\dagger$ ). These values indicate the size of the hydrated exterior hydrophilic layer around the $\mathrm{Gd}_{x}(\mathrm{Kp})_{y}$ based cores in accordance with the core-shell morphology of the colloids (Scheme 1). Small angle X-ray scattering (SAXS) measurements in aqueous solutions of P-123 (0.5 mM) and $\mathrm{P}-123-\mathrm{Gd}_{x}(\mathrm{Kp})_{y}$ show the presence of marked correlation peaks, which indicate the presence of interacting aggregates (Fig. S7 in the ESI $\dagger$ ). The increase in the intensity of SAXS with increasing $\mathrm{Gd}(\mathrm{III})$ concentration indicates the impact of $\mathrm{Gd}^{3+}$ ions in the microheterogeneous phase formation. The Guinier plot analysis revealed the radii of gyration $R_{\mathrm{g}}$ (Fig. S8, ESI $\dagger$ ), which

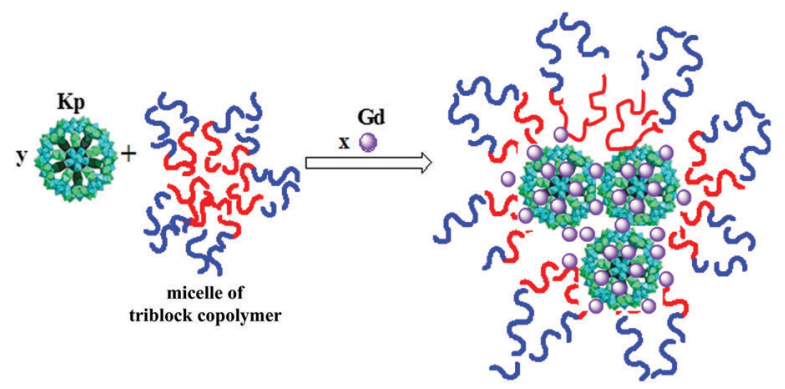

Scheme 1 Schematic presentation of $\mathrm{Gd}_{x}(\mathrm{Kp})_{y}$ colloids stabilized by triblock copolymers. 


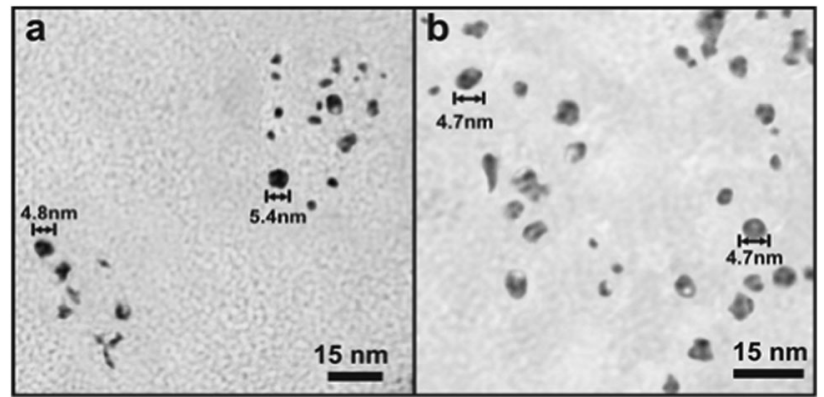

Fig. 2 TEM images of dried samples of $\mathrm{Gd}_{x}(\mathrm{Kp})_{y}$-based colloids stabilized by F-127 (a) and F-68 (b).

were used to calculate the average radii $R_{\mathrm{NP}}$ of P-123 micelles and P-123-Gd ${ }_{x}(\mathrm{Kp})_{y}$ colloids in the assumption of their spherical symmetry.

These $R_{\mathrm{NP}}$ values are 119.3 and $127.7 \AA$ for the micelles and the colloids respectively (for concentration details, see samples 4 and 1 in Fig. S8, ESI $\dagger$ ), which are in good agreement with the diameters obtained using the DLS method. Nevertheless, both DLS and SAXS measurements are affected by the exterior hydrophilic coating of the hard cores, as well as their aggregation. Therefore, transmission electronic microscopy (TEM) imaging of the dried colloids was performed in order to measure the intrinsic sizes of the $\mathrm{Gd}_{x}(\mathrm{Kp})_{y}$-based cores. TEM images of the dried aqueous colloids (Fig. 2) reveal nanoparticles not larger than $5.4 \mathrm{~nm}$.

The size range of $1-5 \mathrm{~nm}$ is optimal for high longitudinal relaxivity of CAs, since it provides both a slow tumbling regime, favourable for high relaxivity, and good accessibility of the Gd(III) centres to water molecules due to their predominant location at the surface of the small-sized cores. ${ }^{11}$

Consequently, longitudinal and transverse magnetic relaxation rates were measured and are plotted in Fig. 3 against the Gd(III) concentration. The relaxivity values $r_{1}$ and $r_{2}$ were calculated from the change in the relaxation rate per concentration unit of Gd(III). The data reveal very high $r_{1}$ and $r_{2}$ values for the $\mathrm{Gd}_{x}(\mathrm{Kp})_{y}$-based colloids, which are larger than those reported for the majority of other Gd(III)-based colloids. This result can be explained both by the tight binding of the $\mathrm{Gd}^{3+}$ by the $\mathrm{Kp}$ polyanions and the efficient hydration of the paramagnetic ions. Moreover, the structure of the triblock copolymers also
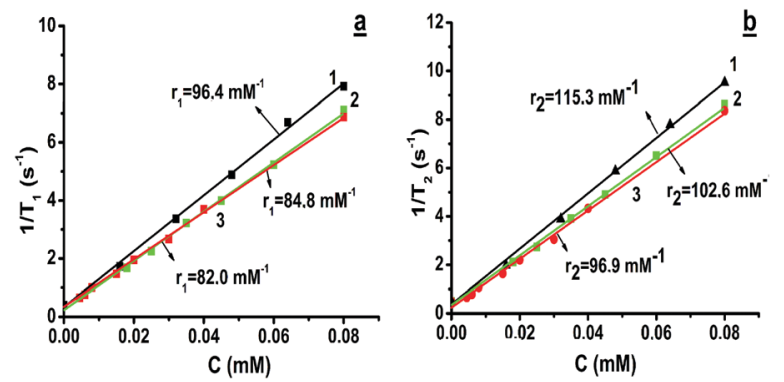

Fig. $31 / T_{1}$ (a) and $1 / T_{2}$ (b) vs. Gd(ı) concentration measured at $25^{\circ} \mathrm{C}$ in $\mathrm{Gd}_{x}(\mathrm{Kp})_{y}$-colloids stabilized by F-127 (1), P-123 (2) and F-68 (3). affects the $r_{1}$ and $r_{2}$ values. In particular, F-127-Gd $(\mathrm{Kp})_{y}$ shows the highest relaxivity, while for P-123 and F-68 the relaxivity is smaller. Taking into account the insignificant difference between the sizes of the $\mathrm{Gd}_{x}(\mathrm{Kp})_{y}$-cores from the TEM images of F-127-and F-68-stabilized colloids (Fig. 2), there must be another factor which is responsible for the difference in relaxivities. For example, the slowed down rotation regime in $\mathrm{Gd}(\mathrm{III})-$ based colloids makes the effect of the water exchange rate on the observed relaxivity critical. ${ }^{27}$ Thus, the hydrophilic shell can be considered to be a factor influencing the exchange rate between water molecules in the inner sphere of $\mathrm{Gd}(\mathrm{III})$ and those in the bulk of aqueous solution. The higher relaxivity of $\mathrm{F}-127-\mathrm{Gd}_{x}(\mathrm{Kp})_{y}$ versus the other colloids points to optimal combination of the rotation and water exchange correlation times, only achieved when (PEO) ${ }_{100}-(\mathrm{PPO})_{65}-(\mathrm{PEO})_{100}$ (F-127) aggregates are applied for the colloid stabilization. Thus, it can be assumed that only F-127 provides the hydrophilic shell of optimal thickness for the $\mathrm{Gd}_{x}(\mathrm{Kp})_{y}$-based cores, required for specific water exchange dynamics to achieve better relaxivity. Nevertheless, the optimization of the $\mathrm{Gd} / \mathrm{Kp}$ concentration ratio provides room for further enhancement of the relaxivity. We found that the relaxation rates (both $1 / T_{1}$ and $1 / T_{2}$ ) remain unchanged within the $\mathrm{Gd} / \mathrm{Kp}$ ratio going down from $c a .10: 1$ to $4: 1$ (Fig. S9, ESI $\dagger$ ). In this respect the work of Müller and coworkers, ${ }^{28}$ highlighting the binding of $\mathrm{Pr}^{3+}$ ions both inside and outside of a keplerate capsule, is worth noting. The coordination sphere of the internal $\mathrm{Pr}^{3+}$ ions is completed by the oxygen atoms of the encapsulated water molecules. ${ }^{28}$ This speciation, if maintained in our case, points to unequal contribution of $\mathrm{Gd}^{3+}$ ions bound to $\mathrm{Kp}$, and precise specification of the binding sites for $\mathrm{Gd}^{3+}$ and their impact on the colloid properties and stability of the $\mathrm{Gd}_{x}(\mathrm{Kp})_{y}$ materials will be the subject of further studies.

Magnetic relaxation rates were monitored for 25 hours with the aim to reveal the effect of time-induced degradation and colloid instability on the relaxivity of the colloids (Fig. 1b). The degradation of $\mathrm{Gd}_{x}(\mathrm{Kp})_{y}$ colloids is fastest in the presence of F-68 (Fig. 1a), which is in a good agreement with the decreased relaxivity of F-68-Gd ${ }_{x}(\mathrm{Kp})_{y}$ after 25 hours (Fig. 1b). Nevertheless, relaxation rates remain practically unchanged for F-127- and P-123stabilized $\mathrm{Gd}_{x}(\mathrm{Kp})_{y}$ within 25 hours, while their UV-Vis spectra do show detectable destruction of the Kp ligands. Thus, some of Kp anions are destructed within 25 hours, although the destruction is not followed by the colloid dissolution, which can result from an insolubility of $\mathrm{Gd}(\mathrm{III})$ complexes with anions produced by the destruction of keplerates. The stability of the F-127- $\mathrm{Gd}_{x}(\mathrm{Kp})_{y}$ colloids enables the measurement of $1 /\left(C_{\mathrm{Gd}} \cdot T_{1}\right)$ and $1 /\left(C_{\mathrm{Gd}} \cdot T_{2}\right)$ values on a whole body scanner at $1.5 \mathrm{~T}$ and $25{ }^{\circ} \mathrm{C}$ (for more details, see the $\mathrm{ESI} \dagger$ ), which were found to be 84.5 and $154 \mathrm{mM}^{-1} \mathrm{~s}^{-1}$, respectively. Taking into account the documented tendency to decrease in $r_{1}$ and increase in $r_{2}$ with the growth in the magnetic field strength, ${ }^{11}$ the measured values correlate with the values obtained at $0.47 \mathrm{~T}$ (Fig. 3), and thus meet the prerequisites for a good contrasting effect in $T_{1}$-weighted MR images.

It is obvious that, to be applied as CAs in MRI of living tissues, the $\mathrm{Gd}_{x}(\mathrm{Kp})_{y}$-based colloids must have low cytotoxicity. 


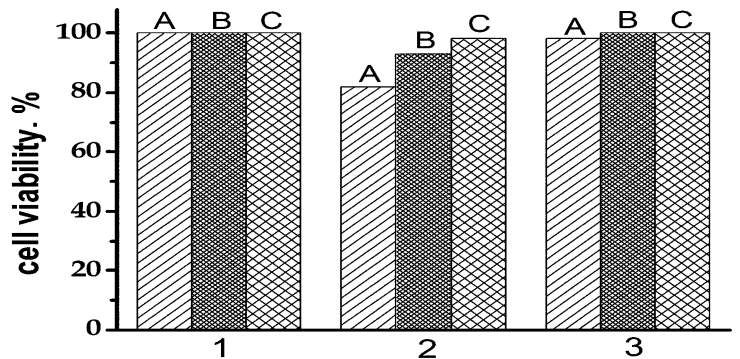

Fig. 4 Cell viability in the presence of $\mathrm{Gd}_{x}(\mathrm{Kp})_{y}$-colloids stabilized by F-127 (1), P-123(2), and F-68 (3) at various concentrations of Gd(III): $0.08(\mathrm{~A}), 0.04(\mathrm{~B})$ and $0.02(\mathrm{C}) \mathrm{mM}$.

Cytotoxicity of free keplerates is rather high due to the toxicity of molybdates produced by their destruction. ${ }^{29}$ In our case, the retarded destruction of the colloids results in the insignificant release of toxic molybdates, which is the main reason for low cytotoxicity of the colloids, although the toxicity of the triblock copolymers can also contribute to the overall cytotoxicity of the colloids. However, high half-maximum inhibitory concentrations ( $\mathrm{IC}_{50}$ ) of F-68 and F-127 (8 and $4.8 \mathrm{mM}$, respectively ${ }^{30,31}$ ) point to their insignificant contribution to the cytotoxicity under the applied concentration conditions, while the higher cytotoxicity of P-123 $\left(\mathrm{IC}_{50}=0.9 \mathrm{mM}^{32}\right)$ can worsen the cell viability in the presence of P-123-stabilized colloids. Fig. 4 shows the cell viability of WI-38 VA 13 subline 2RA in the presence of the colloids with $\mathrm{Gd}(\mathrm{III})$ concentrations adjusted at $0.08,0.04$ and $0.02 \mathrm{mM}$, which in turn correspond to high $1 / T_{1}$ and $1 / T_{2}$ values (Fig. 3). The results (Fig. 4 ) indeed indicate very low cytotoxicity of the synthesized colloids when F-68 and F-127 are applied for colloid stabilization, while some increase in cytotoxicity of the P-123-stabilized colloids results from the higher contribution of P-123 to the overall cytotoxicity.

\section{Conclusions}

The work introduces a facile one-pot synthesis of new hydrophilic Gd(III)-based colloids with very high longitudinal relaxivity, convenient colloid stability and low cytotoxicity. The architecture of $\mathrm{Gd}_{x}(\mathrm{Kp})_{y}$ complexes, where $\mathrm{Gd}^{3+}$ ions are tightly bound to and within the Keplerate polyanions while remaining efficiently hydrated due to the large amount of coordination and crystalline water, is the reason for high relaxivity. The optimization of the size and hydrophilization of the $\mathrm{Gd}_{x}\left(\mathrm{Kp}_{y^{-}}\right.$ based cores results in the convenient (for practical use) stability (slow degradation of the $\mathrm{Kp}$ and slow release of $\mathrm{Gd}^{3+}$ after $\mathrm{Kp}$ degradation), and, consequently, low cytotoxicity.

\section{Acknowledgements}

We thank RSF (grant no 17-13-01013) for financial support. TEM images were obtained in the laboratory "Transmission electron microscopy" of Kazan National Research Technological University.

\section{Notes and references}

1 H. B. Na, I. C. Song and T. Hyeon, Adv. Mater., 2009, 21, 2133-2148.

2 F. Wang, E. Peng, B. Zheng, S. F. Y. Li and J. M. Xue, J. Phys. Chem. C, 2015, 119, 23735-23742.

3 J. Y. Park, M. J. Baek, E. S. Choi, S. Woo, J. H. Kim, T. J. Kim, J. C. Jung, K. S. Chae, Y. Chang and G. H. Lee, ACS Nano, 2009, 3, 3663-3669.

4 M. Cho, R. Sethi, J. S. A. Narayanan, S. S. Lee, D. N. Benoit, N. Taheri, P. Decizzi and V. Colvin, Nanoscale, 2014, 6, 13637-13645.

5 J. Fang, P. Chandrasekharan, X. L. Liu, Y. Yang, Y. B. Lv, C. T. Yang and J. Ding, Biomaterials, 2014, 35, 1636-1642.

6 W. Hatakeyama, T. J. Sanchez, M. D. Rowe, N. J. Serkova, M. W. Liberatore and S. G. Boyes, ACS Appl. Mater. Interfaces, 2011, 3, 1502-1510.

7 A. Carne-Sanchez, C. S. Bonnet, I. Imaz, J. Lorenzo, E. Toth and D. Maspoch, J. Am. Chem. Soc., 2013, 135, 17711-17714.

8 M. D. Rowe, C.-C. Chang, D. H. Thamm, S. L. Kraft, J. F. Harmon, Jr., A. P. Vogt, B. S. Sumerlin and S. G. Boyes, Langmuir, 2009, 25, 9487-9499.

9 W. J. Rieter, K. M. L. Taylor, H. An, W. Lin and W. Lin, J. Am. Chem. Soc., 2006, 128, 9024-9025.

10 K. M. L. Taylor, W. J. Rieter and W. Lin, J. Am. Chem. Soc., 2008, 130, 14358-14359.

11 P. Caravan, C. T. Farrar, L. Frullano and R. Uppal, Contrast Media Mol. Imaging, 2009, 4, 89-100.

12 Md. W. Ahmad, W. Xu, S. J. Kim, J. S. Baeck, Y. Chang, J. E. Bae, K. S. Chae, J. A. Park, T. J. Kim and G. H. Lee, Sci. Rep., 2015, 5, 8549.

13 M. S. Tarasenko, E. O. Golenkov, N. G. Naumov, N. K. Moroz and V. E. Fedorov, Chem. Commun., 2009, 2655-2657.

14 S. B. Artemkina, N. G. Naumov, A. V. Virovets and V. E. Fedorov, Eur. J. Inorg. Chem., 2005, 1, 142-146.

15 A. Müller, E. Krickemeyer, H. Bögge, M. Schmidtmann, C. Beugholt, P. Kogerler and C. Lu, Angew. Chem., Int. Ed., 1998, 37, 1220-1223.

16 M. Rubcic, V. S. Korenev, L. Toma, H. Bögge, V. P. Fedin and A. Müller, Inorg. Chem. Front., 2014, 1, 740.

17 L. Zhang, Y. Zhou and R. Han, Eur. J. Inorg. Chem., 2010, 2471-2475.

18 J. Koetz and S. Kosmella, Polyelectrolytes and Nanoparticles, Springer, Leipzig, 2007.

19 O. V. Kharissova, B. I. Kharisov, V. M. Jimenez-Perez, B. M. Flores and U. O. Mendez, RSC Adv., 2013, 3, 22648-22682.

20 N. Suthiwangcharoen and R. Nagarajan, RSC Adv., 2014, 4, 10076-10089.

21 A. A. Ostroushko and M. O. Tonkushina, Russ. J. Phys. Chem., 2016, 90, 436-442.

22 G. Wanka, H. Hoffmann and W. Ulbricht, Colloid Polym. Sci., 1990, 268, 101-117.

23 P. Alexandridis, V. Athanassiou, S. Fukuda and T. A. Hatton, Langmuir, 1994, 10, 2604-2614.

24 E. Batrakova, Sh. Lee, Sh. Li, An. Venne, V. Alakhov and A. Kabanov, Pharm. Res., 1999, 16, 1373-1379. 
25 J. R. Lopes and W. Loh, Langmuir, 1998, 14, 750-756.

26 J. Elistratova, M. Mikhailov, V. Burilov, V. Babaev, I. Rizvanov,

A. Mustafina, P. Abramov, M. Sokolov, A. Konovalov and V. Fedin, RSC Adv., 2014, 4, 27922-27930.

27 G. A. Pereira, J. A. Peters, F. A. A. Paz, J. Rocha and C. F. G. C. Geraldes, Inorg. Chem., 2010, 49, 2969-2974.

28 A. Müller, Yu. Zhou, H. Bögge, M. Schmidtmann, T. Mitra, E. T. K. Haupt and A. Berkle, Angew. Chem., 2006, 45, 460-465.
29 F. V. Michelis, A. Delitheos and E. Tiligada, J. Trace Elem. Med. Biol., 2011, 25, 138-142.

30 A. A. Exner, T. M. Krupka, K. Scherrer and J. M. Teets, J. Controlled Release, 2005, 106, 188-197.

31 Y. C. Chen, H. D. Liang, Q. P. Zhang, M. K. Blomley and Q. L. Lu, Ultrasound Med. Biol., 2006, 32, 131-137.

32 Y. Guan, J. Huang, L. Zuo, J. Xu, L. Si, J. Qiuand and G. Li, Arch. Pharmacal Res., 2011, 34, 1719-1728. 